\title{
Profile of Hand Surgery Cases at Kirtipur Hospital
}

\author{
Karki $\mathrm{B}^{1}$, Nakarmi K${ }^{2}$, Magar $\mathrm{MG}^{3}$, Nagarkoti K $\mathrm{K}^{4}$, Rai $\mathrm{SM}^{5}$
}

\begin{abstract}
Background: There can be multiple hand problems with which patients can present. Such hand problems can be because of any kind of trauma, birth defects, tumours, infection or other conditions. Hand surgery is a special field of plastic surgery, which deals with these hand problems. The Department of Burns, Plastic \& Reconstructive Surgery of Kirtipur Hospital run by Public Health Concern Trust-Nepal has been providing hand surgery service to the patients with these hand problems. Aim of Study: To analyse the various types of surgical hand problems in patients attending Kirtipur Hospital. Material and Methods: It is a cross sectional retrospective observational study of the patients with different hand problems done at the Department of Burns, Plastic \& Reconstructive surgery of Kirtipur Hospital from January to December 2016. Results: There were 124 patients who presented with various hand problems. There was male preponderance and the most common age group affected was between 15-60 years. Hand trauma was the most common cause of hand problems followed by post burn contractures. Conclusion: Hand is a complicated organ which can give rise to various problems. Hand surgery is an essential component of reconstructive surgery to deal with these problems.
\end{abstract}

Key words: Congenital hand anomalies, hand problems, hand Surgery, traumatic hand

\section{INTRODUCTION}

Hand is a complex organ, which has motor and sensory functions. It is composed of different heterogeneous tissues such as skin, bone, muscles, nerve, vessels and ligaments. Because of this fact, multiple pathological conditions can arise from it. Hence, hand surgery is a separate specialty, which deals with these problems. Hand trauma is one of the most common injuries because it is most prehensile organ frequently exposed to external surrounding. It can be due to sports-related, war, accidents or even daily activity ${ }^{1}$.

A congenital hand anomaly is a rare condition with about 3.45.3 per 10000 live births. Every reconstructive surgeon should have a basic knowledge about these conditions, which can sometimes be associated with life-threatening conditions ${ }^{2}$. Patients can present with tumours of hand. The treating surgeon requires a high index of suspicion so that the tumours are not missed. Early identification and treatment of malignant lesions can prevent not only the amputation but also the mortality ${ }^{3}$. The hand is ranked as one of the three most frequent sites of burn scar contracture deformity. This can significantly affect the quality of life. Appropriate and early treatment can

\footnotetext{
1. Dr. Bishal Karki

2. Dr. Kiran Nakarmi

3. Dr. Mangal Gharti Magar

4. Dr. Krishna Nagarkoti

5. Prof. Dr. Shankar Man Rai
}

Address for correspondence:

Dr. Bishal Karki

Department of Burns,

Plastic \& Reconstructive Surgery

Kirtipur Hospital, Kirtipur, Kathmandu, Nepal

Email: bishal_karki32@yahoo.com prevent these contractures ${ }^{4}$. Department of Plastic Surgery under Public Health Concern Trust-Nepal has been treating patients with different hand problems. Department of Plastic Surgery has been keen on improving hand surgery service from the beginning of the opening of the service.

In Nepal there is inadequate information about epidemiology of Hand surgery. Thus this present study aims to find out the epidemiology of the hand problems eg age, gender, geographical area, various causes of hand problems and the various treatment provided.

\section{MATERIAL AND METHODS}

This was a retrospective study done from January to December 2016. Ethical approval was taken from institutional review board prior to the study. Clinical records of the patients who had undergone treatment in the Department of Burns, Plastic and Reconstructive Surgery in Kirtipur Hospital were reviewed. All patients who received hand surgical interventions were included in this study. Demographics of the patients and the wound characteristics were summarized by descriptive statistics. Continuous variables were expressed as median (SD) unless stated otherwise and categorical variables were presented as percentages.

All the data were tabulated in Excel sheet and analysed using Microsoft Office Excel 2007.

\section{RESULTS}

A total of 124 hand operations were conducted during study period. There was male predominance among the total patients with male to female ratio of $1.25: 1$. The gender distribution is shown in Figure 1. 


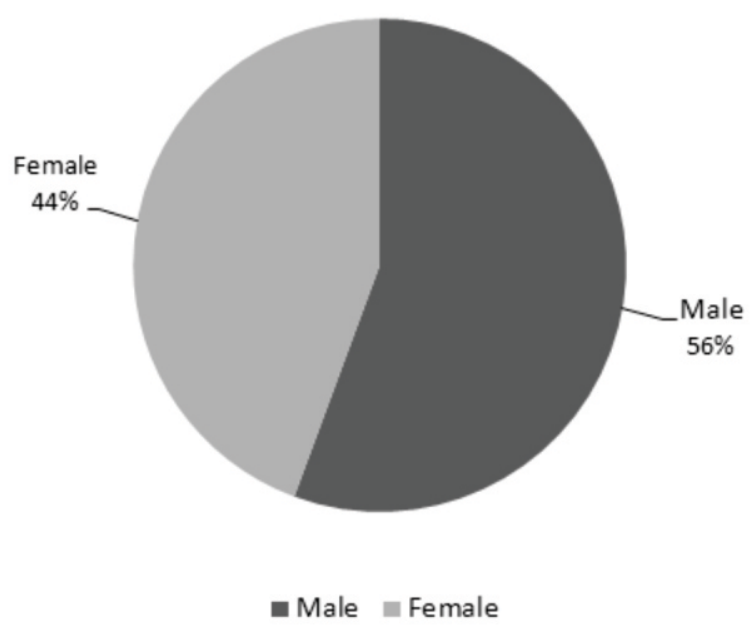

Figure 1: Gender distribution of the patients with hand problems

The mean age of the patient was 23.5 years with standard deviation of 15.23. The age distribution is shown in Table I.

\begin{tabular}{|c|c|c|}
\hline Age group (years) & No. of pts. & \% \\
\hline$<15$ years & 39 & $31.5 \%$ \\
\hline $15-60$ years & 80 & $64.5 \%$ \\
\hline$>60$ years & 5 & $4 \%$ \\
\hline
\end{tabular}

Table I: Distribution of Hand surgery cases in different age groups

The most common causes for surgical interventions were traumatic cases (51.6\%) followed by post burn contracture (32.8\%). Other causes were congenital malformation of hand, benign tumors, Dupuytren's contracture and malignant tumor. $4.8 \%$ cases came with other miscellaneous conditions like traumatic flexion contracture of ring finger, ulnar nerve paralysis, VIC, boutonniere deformity and hypertrophic scars.

\begin{tabular}{|c|c|c|}
\hline Causes & No. of pts. & \% \\
\hline Trauma & 64 & $51.6 \%$ \\
\hline Post burn contracture & 40 & $32.8 \%$ \\
\hline Congenital malformation & 5 & $4 \%$ \\
\hline Benign tumors & 4 & $3 \%$ \\
\hline Dupuytren's contracture & 4 & $3 \%$ \\
\hline Malignant tumors & 1 & $0.8 \%$ \\
\hline Misc & 6 & $4.8 \%$ \\
\hline
\end{tabular}

Table II: Different causes of hand problems
Out of total 64 hand injuries, most common was fingertip injury $30(46 \%)$ followed by laceration (21), fracture (7), tendon injury (6), amputation (11) and nerve palsy (1).

Commonest congenital anomaly operated during our study period were syndactyly, polydactyly and amniotic band syndrome.

There were 5 cases of hand tumors (4\%) who underwent surgical intervention in our center as shown in Table III.

\begin{tabular}{|c|c|c|}
\hline \multicolumn{2}{|l|}{ Benign } & \multirow{5}{*}{$4 \%$} \\
\hline Ganglion & 3 & \\
\hline Giant Cell tumor & 1 & \\
\hline \multicolumn{2}{|l|}{ Malignant } & \\
\hline $\begin{array}{l}\text { Malignant Peripheral } \\
\text { nerve sheath tumor }\end{array}$ & 1 & \\
\hline
\end{tabular}

Table III: Hand tumors

All the patients underwent different types of surgical procedures. Fingertips repair with local flaps and post burn contracture release with local flaps and skin grafts were the most common surgeries. Other surgeries were repair of tendons, fracture reduction and fixation, tendon transfer for nerve palsy and excision of tumors. Free anterolateral thigh flap was used to reconstruct an electrical burn hand.
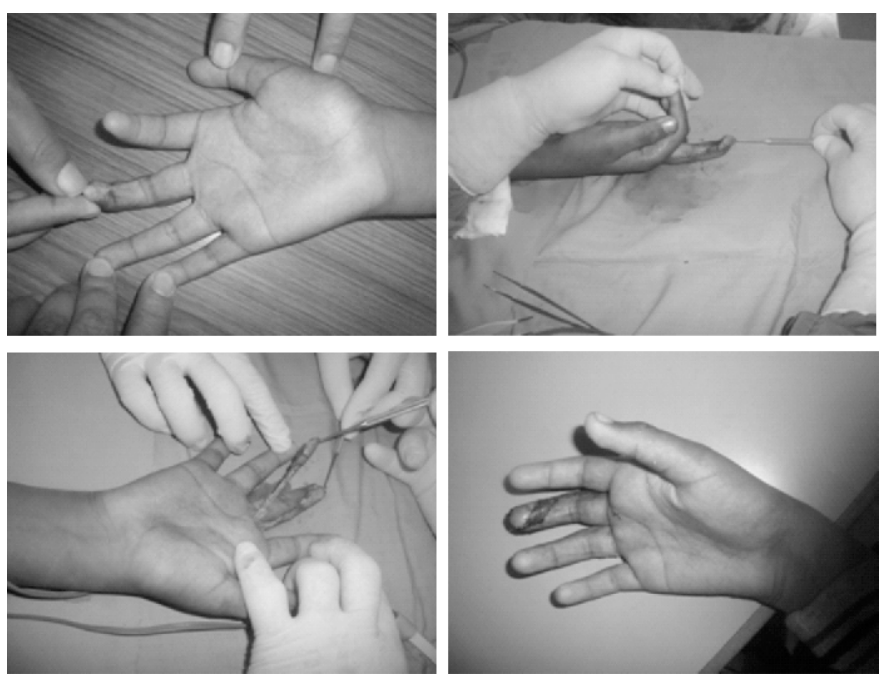

Figure 2: Soft tissue sensate coverage of the tender fingertip following crush injury with homodigital island flap based on radial digital neurovascular bundle and full thickness skin graft. 

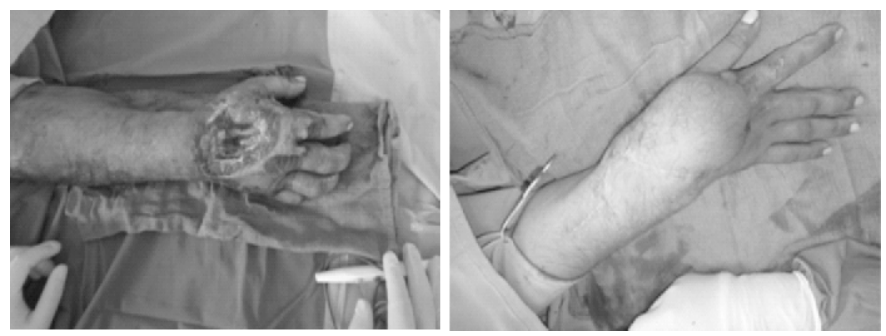

Figure 3: Soft tissue coverage of Grade IV electrical burn of right hand with free anterolateral thigh flap after debridement.

\section{DISCUSSION}

So far no scientific studies are available to highlight the common hand surgical cases and common hand operative procedures in Nepal. Hand surgery is a broad term that covers many different types of procedures. We, team of plastic surgeons in Kirtipur Hospital perform hand surgery to restore hand and finger function and also try to make hand look as normal as possible.

Most of the cases that underwent hand surgical procedure were of hand injury cases. In our study the spectrum of hand injury ranged from simple laceration which were easily repaired to multiple finger amputations and crush injury which required extensive and multiple reconstructive surgeries. Hand surgical cases were predominantly seen in male which is similar to the study conducted in India about hand injury cases ${ }^{5,6}$.

In this study we found among 124 cases who were operated, $64.5 \%$ were in age group of $15-60$ years. This may be because the commonest case to undergo hand surgery were hand injury cases which occurs more in this age group suggested by other studies $^{6-8}$.

The most common form of hand injury was fingertip injury in our study which is consistent with the study done by Bazroy et al in Puducherry, India. They found that the commonest types of injuries were cuts and lacerations $(50.1 \%)^{9,10}$. This is because of the fact that the hand is the organ which is frequently exposed to the external environmental insults.The hand is ranked among the three most frequent sites of burns scar contracture deformity. In our study $32.8 \%$ of the cases of the hand surgery were post burn contracture. As described in other studies, these patients were managed with contracture release with local flap and skin graft ${ }^{11-13}$.

Syndactyly and polydactyly are the most common form of congenital hand differences in this study which is consistent with other studies14,15. Ganglion followed by giant cell tumor of the tendon sheath were the most common hand tumors. This is similar to other studies ${ }^{16,17}$.

\section{CONCLUSION}

Hand problems can have a wide spectrum of pathologies ranging from the birth defects to tumour. The most common cause is trauma. Hand surgery is a subspecialty of plastic surgery which can deal with all these problems.

\section{REFERENCE}

1. Pilling T, Govender P. Profile and management of the fireworkinjured hand. S Afr Med J. 2016;58(2):48-53.

2. Dy CJ, Swarup I, Daluiski A. Embryology, diagnosis, and evaluation of congenital hand anomalies. Curr Rev in Musculoskelet Med. 2014;7(1):60-7.

3. Thomas BP, Sasi K, Pallapati SCR, Mathew A, Sreekanth R, Thomas $M$. Malignant tumours of the hand and wrist. Indian J Plast Surg 2011;44(2):337-47.

4. Sabapathy SR, Bajantri B, Bharathi RR. Management of post burn hand deformities. Indian J Plast Surg 2010;43(Suppl):S72-S9.

5. Gupta A, Gupta AK, Uppal SK, Mittal RK, Garg R, Aggarwal N. Demographic Profile of Hand Injuries in an Industrial Town of North India: A Review of 436 Patients. Indian J Surgery. 2013;75(6):454-61.

6. Shrihari V. Spectrum of hand injuries and their management at a tertiary care hospital using the hand injury scoring system. Int Surg J. 2016;3(4):6.

7. Trybus $M$, Tusinski $M$, Guzik P. Alcohol-related hand injuries. Injury. 2005;36(10):1237-40.

8. Sorock GS, Lombardi DA, Hauser RB, Eisen EA, Herrick RF, Mittleman MA. Acute Traumatic Occupational Hand Injuries: Type, Location, and Severity. J Occup Environ Med 2002;44(4):345-51.

9. Bazroy J, Roy G, Sahai A, Soudarssanane MB. Magnitude and risk factors of injuries in a glass bottle manufacturing plant. J Occup Health. 2003;45(1):53-9.

10. Hung LK, Choi KY, Yip K, Chan J, Leung PC. Recent changes in the pattern of hand injuries in Hong Kong: a regional hospital survey. Hong Kong Med J 1997;3(2):141-8.

11. Schneider JC, Holavanahalli R, Helm P, Goldstein R, Kowalske K. Contractures in burn injury: defining the problem. J Burn Care Res 2006;27(4):508-14.

12. Schneider JC, Holavanahalli R, Helm P, O'Neil C, Goldstein R, Kowalske K. Contractures in burn injury part II: investigating joints of the hand. J Burn Care Res 2008;29(4):606-13.

13. Sabapathy S, Bajantri B, Bharathi R. Management of post burn hand deformities. Indian J Plast Surg 2010;43(3):72-9.

14. Abulezz T, Talaat M, Elsani A, Allam K. Congenital hand anomalies in Upper Egypt. Indian J Plast Surg 2016;49(2):206-13.

15. Mody N, Srinivasan S, Thatte M. Cross-sectional study of epidemiology of congenital anomaly of the hand in a tertiary care centre in India over 1 year. Indian J Plast Surg 2016;49(3):424-5.

16. McPherson T. Benign tumors of fibrous tissue and adipose tissue of the hand. J Hand Therapy.18(1):53-4.

17. Sobanko JF, Dagum AB, Davis IC, Kriegel DA. Soft Tissue Tumors of the Hand. 2. Malignant. Dermatol Surg. 2007;33(7):771-85. 